always increases from the surface of the ground up to 1800 feet above sea-level, and that the ratio of the increase steadily diminishes up to that height. The only exception to the steady decrease in the value of $x$ occurs in Group 5, and this is evidently due to the inclusion in that group of an abnormally large value of $x(0.576)$, corresponding to an equally abnormally small velocity of 789 feet per minute, which is little more than a third of the mean velocity of the stratum corresponding to that group. The mean velocities of each group are also seen to increase with some degree of regularity with the height, but this is, of course, partly accidental. In estimating the value of the exponent $x$ for strata of the atmosphere at different heights above sea-level, it must be remembered that the place of observation is 500 feet above sea-level, and therefore that at a certain height above the ground the motion of the air in all probability approximates to what it would have at its real height above the sea. Where this state of things actually occurs, we have no ready means of determining, but at a height of Iooo feet above the ground we may assume that the influence of the subjacent tableland is almost obliterated, and the motion of the air approximates to what it would have at its real sea-level height. On this assumption, if we add the full 500 feet to each height in Group 6, we get the following value for the exponent :-

$\begin{array}{cccc}\text { Gppar sea-level } & \begin{array}{c}\text { Lower sea-level } \\ \text { height } \\ \text { I } 267\end{array} & \text { Value of } x \\ \text { Group } 6 & \text { I595 } & 0.28\end{array}$

If more reasonably we add 400 feet only, we get $x=0.26$, or almost identically the same value as 0.25 , which I found agree best on the average with Dr. Vettin's cloud observations at Berlin, ranging from 1600 to 23,000 feet above sea-level (NATURE, January II, 1883). I think, therefore, that the results of the present series of observations may be taken to add strong confirmation to the general agreement of the empirical formula $\frac{V}{v}=\left(\frac{H}{h}\right)^{0.2 s}$, with the average motion of the air at heights over 1600 above sea-level.

One great advantage which results from the representation of the observations in the form of exponents is that we are thus enabled to compare observations differing from one another, both as to height and velocity, in a manner which would otherwise be almost impossible.

There are four principal variables which have been observed, and which are likely to affect the value of these exponents, viz. (I) the mean velocity at the upper and lower elevations ; (2) the direction of the wind; (3) the time of day ; and (4) the month of the year. I have, so to speak, differentiated the exponents with respect to each of these variables in turn, and have in each case placed the corresponding values of the other variables alongside, in order to see how much of the resulting variation of the exponent is independent, or dependent on accidental collocations of the other variables. The results I find most curiously involved, owing to apparently accidental groupings of some of the variables.

One or two variations can, however, be shown to arise from the infuence of one factor alone, after that due to the coexistence of others is allowed for. One of these is that due to the change of mean velocity, and the other is the diurnal change with the hour of the day. These are shown in the accompanying Tables II. and III. respectively.

In Table II. the exponent is found, on the whole, to increase with an increase in the velocity in the two lowest groups ( $I$ and 2 ), and to decrease in the four upper groups, the maxima in each of these groups occurring at the lower velocities, and the minima at the highest ones.

Thi; latter result is what might have been expected a priori, and though the first two groups would appear at first sight to present an anomaly, it must be remembered that in these groups the lower instrument is hardly above the influence of surrounding trees, so that in high winds, while the upper instrument might be feeling the full force of the wind, the lower one might be unduly sheltered from it by adjacent trees or buildings.

In Table III. the diurnal variation in the value of the exponents, reaching its minimum from 2 to 3 or 3 to 4 , and its maximum between 6 and 8 (as far as the observations go), is most clearly and regularly shown in each of the four upper groups, and as these last are well beyond the influence of local obstructions, I regard the uniformity with which they exhibit this variation as a strong proof in favour of its physical existence independently of any similar variation caused by the parallel march of other factors. Even if part of the variation in groups 3, 4, and 6 is due to the equally regular decrease in the mean velocity from midday to evening, it can be shown from Table II. that this only accounts for a portion of the observed variation.

Thus, taking the ranges of the exponents in Table III., and adding to or subtracting from them the proportional ranges of the exponents for the corresponding opposite range of velocity (deduced from the mean range of the exponents for 400 feet range of velocity in Table II.), we get the following results :-

Ranges of exponents from diurnal minimum to

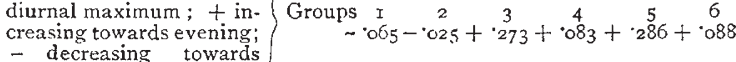
evening.

that is to say, for Group 5 the variation is increased, and for the rest not materially diminished.

The opposite variation in the two lowest groups ( $I$ and 2) may be capable of an explanation somewhat analogous to the similar anomaly presented by these two groups in Table II., but in any case it cannot be said either to sensibly corroborate or invalidate the physical existence of the variation so statistically marked in all the four upper groups.

This diurnal change in the value of the ratio of the velocity of the upper to the lower strata which is here shown to occur for the afternoon hours, is confirmed by various other casual observations, and is in complete accord with the results afforded by anemometrical observations on Ben Nevis and other lofty mountain observatories, as well as with Dr. Köppen's theory of the diurnal period in the surface-wind alluded to in my former paper.

Since at stations near sea-level the diurnal wind-velocity reaches its maximum at midday and its minimum at midnight, while at lofty stations about 4000 feet above sea-level the critical epochs are reversed, it is evident that somewhere between these levels a neutral plane exists where the diurnal variation is nil. The ratio of the upper velocity to the lower for a given difference of height would, however, continue to vary diurnally all the way up (unless some unknown law intervene), reaching its minimum value about midday and its maximum about midnight.

Indications of other laws have been noticed in the value of the exponents, such as $a^{*}$ maximum for west winds and a minimum for east winds in five out of six of the groups, and also a maximum in the autumn, minimum in the winter, and maximum again in the summer in all the groups, but the observations are too few and the factors too involved to establish these with any certainty. I trust on a future occasion to be able to go into these questions more in detail, and also to supply the morning half of the diurnal variation, which I consider to be the most certain and valuable result $I$ have as yet obtained in addition to the law of the general progressive decrease in the value of the exponent up to 1800 feet above sea-level in the free atmosphere. E. Douglas Archibald

\section{BASIC CINDER}

THE interest of this report centres principally around the question of the manurial value of undissolved phosphates present in basic steel slag or cinder. The basic cinder is the effete and broken up basic lining of the converters used in the Thomas and Gilchrist process for dephosphorising iron, and is made in very large quantities as a by-product of steel manufacture. It contains from 16 to 19 per cent. of phosphoric acid in union with lime and other bases in combinations insoluble in water.

At the request of the North-Eastern Steel Company Prof. Wrightson and Dr. Munro undertook field experiments in order to test the manurial value of this substance. These experiments were carried out last summer on the College farm at Downton, and at East Howle, Ferry Hill, county of Durham, upon dissimilar soils, and under different climatic conditions. The results as given in the very concise report before us are remarkable, and certainly must be highly satisfactory to those who are interested in the future of basic cinder. The value of this substance as a fertiliser for swedes and turnips, as well as for grass, is placed beyond reasonable doubt by a most remarkable unanimity of results obtained at both experimental stations. Each series

I "Report on Experiments made to test the Manurial Value of Basic Cinder from the North-Eastern Steel Works." By Prof Wrightson and Dr. Munro, of the College of Agriculture, Downton, Salisbu'y. Middlesbrough : Daily Exchange Offices, 1886 
was composed of thirty-five plots of one chain square, or of onetenth of an acre each, and comprised forty drills or row's of plants. The plots were arranged to form five rows of seven plots each, and a rectangle of three and a half acres. They were so disposed within this area that every manured plot was adjacent to an unmanured plot, with the object of obtaining repeated confirmations of any differences which might be indicated in favour of the dressings. Every trial was made in duplicate in both series, and the results are graphically shown by tinted plans, on which the number of the plot, the manurial dressing used, and the number and weight of roots grown are printed.

Not only do these experiments prove ground basic cinder to be a valuable fertiliser, but they assign it a higher position than ground coprolite, and place it only slightly below "superphosphate" in value. This remarkable result is, we find, supported by statements resting on the authority of Dr. Biedermann Centralblatt (vol. xiv. part 2), in which the phosphoric acid in basic cinder is asserted to be more readily appropriated by growing plants than is the phosphoric acid contained in coprolites.

The subject is full of interest as bearing upon the positive profits of steel manufacture, and also upon the manufacture of superphosphate and upon agricultural practice. It has attracted the attention of M. Grandeau, of the Faculty of Science of the French University, who contributed a review of the pamphlet before us occupying over three columns of Le Temps newspaper. In the course of his remarks he says :- "Les résultats obtenus en Angleterre confurment pleinement, on le voit, ceux que les agronomes allemands ont publiés et que j'ai précédemment analysés. Les scories de déphosphoration sont appelées à jouer un rôle consiclérable dans la fumure du sol. Des négociants ont déjà traité avec quelques-unes des importantes usines de l'Est (Alsace-Lorraine notamment) pour l'achat de toute leur production de scories."

The experiments conducted at Downton and Ferry Hill were not only instituted to ascertain the positive value of ground basic cinder in comparison with unmanured plots. In them the ground cinder was compared with ground coprolite, with ordinary superphosphate, with a rich superphosphate, with a superphosphate made direct from the basic slag, and with a superphosphate to which green vitriol was added. The subject is likely to arouse a very considerable amount of attention.

\section{AN IMPROVED FORM OF TEMPERATURE REGULATOR}

$\mathrm{N}_{\mathrm{N}} \mathbf{8 8 2}$, at the request of the Board of Trade, the Royal Society appointed a Committee, consisting of Sir G. Airy, Col. Clark, and Prof. Stokes, to advise on the question of improving the existing means of the comparison of standards of length at the Standard Office. In their report the Committee suggested improvements in the arrangement for securing greater uniformity and steadiness of temperature in the bars under comparison. As a first step in this direction, the Cambridge Scientific Instrument Company were requested to investigate the subject of temperature regulators, and to consider the general design of a comparing apparatus. They proposed that the standards, some hours before they were observed, should be placed in metal cases and immersed in a bath containing water; and that they should not be disturbed during the process of observation. If the uniformity of temperature of the water could be ensured, it would secure the equality of temperature of the standards and remove one of the greatest difficulties in the construction of a satisfactory comparing apparatus.

After some preliminary trials a regulator was constructed similar to that used at the Bureau International des Poids et Mesures at Sères. ${ }^{1}$ Its action depends on the variation of pressure of a saturated vapour, caused by a change of temperature. The pressure on the volatile liquid and vapour is due to the atmosphere, as well as to a column of mercury ; consequently the regulated temperature will vary with any change in the atmospheric pressure. In the following experiments the corresponding change of temperature for one inch alteration of the barometer was about $0^{\circ} 37 \mathrm{C}$. The accuracy of the regulator therefore depends on the constancy of the atmospheric pressure,

I See "Travaux et Mémoires du Bureau International des Poids et and to overcome this serious disadvantage an arrangement was devised for maintaining a constant pressure on the volatile liquid.

An iron bath, D (Fig. I), containing water, was placed in a wooden box. The intermediate space was filled with sawdust ; this was done to minimise the unequal cooling due to the varying temperature of the room. The two ends of a $U$-shaped tube were fixed into the bottom of the iron bath and passed through holes in the side of the wooden box. The water was kept warm by means of two gas-flames placed under a part of this tube. One of the gas-flames was connected to the regulator and the other direct to the gas-main. The object of the second flame was to re-light the regulated gas-jet in case it should have been extinguished by the regulator.

The water in the bath was kept thoroughly stirred by air forced through it by means of bellows. These were placed inside the box in order to keep them warm, and also for the more important reason of avoiding the currents of air which would otherwise be produced at each stroke. The air used for

\section{Fia 1}

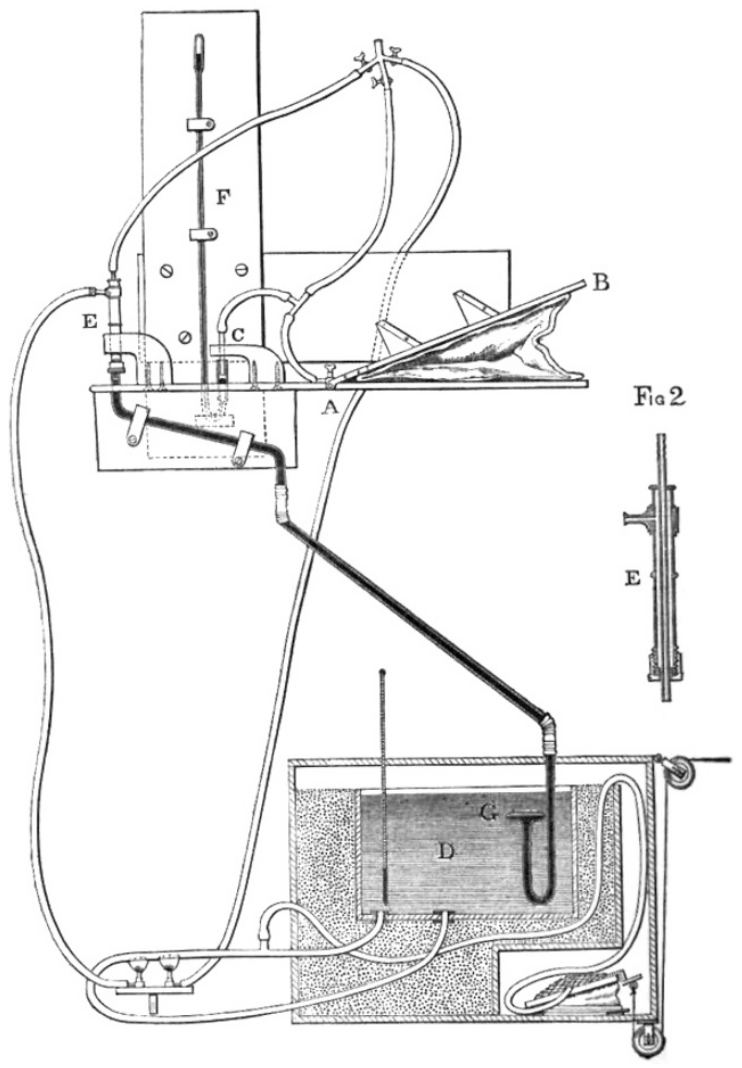

stirring was thus saturated with aqueous vapour, and did not cool the water in the bath by absorbing moisture from it. The nozzle of the bellows was connected to the $U$-shaped tube by a branch inserted just above the point where the gas-flame was applied. The air thus pumped through the upper part of the $U$-tube caused a rapid circulation of water through it. This method has the advantage of applying the heat in a manner which does not tend to make the water in one part of the bath perceptibly hotter than the rest.

The volatile liquid in the regulator was a mixture of methyl-chloride and ethyl-chloride, boiling at about $23^{\circ} \mathrm{C}$ under the normal atmospheric pressure. It was contained in a flat bulb, G, blown at the end of a glass tube, and was under a head of mercury. The glass tubes containing the mercury were connected by short lengths of canvaslined india-rubber tube. A double brass tube was secured to the open end of the regulator, $\mathrm{E}$; this is shown enlarged in 